\title{
Sexual Enhancement Products for Sale Online: Raising Awareness of the Psychoactive Effects of Yohimbine, Maca, Horny Goat Weed, and Ginkgo biloba
}

\author{
Ornella Corazza, ${ }^{1}$ Giovanni Martinotti, ${ }^{2}$ Rita Santacroce, ${ }^{1,2}$ Eleonora Chillemi, ${ }^{2}$ \\ Massimo Di Giannantonio, ${ }^{2}$ Fabrizio Schifano, ${ }^{1}$ and Selim Cellek ${ }^{3}$ \\ ${ }^{1}$ School of Life and Medical Sciences, University of Hertfordshire, College Lane, Hatfield AL10 9AB, UK \\ ${ }^{2}$ Department of Neuroscience and Imaging, University "G. d’Annunzio", 66100 Chieti, Italy \\ ${ }^{3}$ Cranfield University, Bedfordshire MK43 OAL, UK \\ Correspondence should be addressed to Ornella Corazza; o.corazza@herts.ac.uk
}

Received 24 February 2014; Revised 23 May 2014; Accepted 26 May 2014; Published 15 June 2014

Academic Editor: Zsolt Demetrovics

Copyright (c) 2014 Ornella Corazza et al. This is an open access article distributed under the Creative Commons Attribution License, which permits unrestricted use, distribution, and reproduction in any medium, provided the original work is properly cited.

Introduction. The use of unlicensed food and herbal supplements to enhance sexual functions is drastically increasing. This phenomenon, combined with the availability of these products over the Internet, represents a challenge from a clinical and a public health perspective. Methods. A comprehensive multilingual assessment of websites, drug fora, and other online resources was carried out between February and July 2013 with exploratory qualitative searches including 203 websites. Additional searches were conducted using the Global Public Health Intelligence Network (GPHIN). Once the active constitutes of the products were identified, a comprehensive literature search was carried out using PsycInfo and PubMed. Results. The most common sexual enhancement products available on the Internet were identified. Their active ingredients included yohimbine, maca, horny goat weed and Ginkgo biloba. These four substances were reported with the occurrence of adverse events and the induction of psychological symptoms, such as mood changes, anxiety, and hallucinations as well as addictive behaviours. Conclusions. Uncontrolled availability of sexual enhancement products that contain potentially harmful substances is a major public health concern. The possible impact on population health, particularly among subjects with psychiatric disorders, usually at risk for sexual dysfunction, may be significant. This new trend needs to be extensively studied and monitored.

\section{Introduction}

The use of food and herbal supplements to enhance erectile function as well as sexual arousal and desire has become increasingly popular in the recent years $[1,2]$. These products are advertised on the Internet as "natural" and "safer" alternatives to pharmaceutical products, such as gold standard for treatment of erectile dysfunction and the phosphodiesterase type 5 (PDE5) inhibitors (e.g., sildenafil, tadalafil, and vardenafil). However, they often contain potent active constituents [3-5], which remain undeclared on the packaging $[6,7]$. The effects of the aforementioned products, thus, remain unknown until reports on harms expose the problem and accurate clinical evaluation takes place.
Since herbal supplements are plant products, they are generally perceived and hence marketed as natural and, therefore, "safe" [8]. However, several case reports of side effects to herbs and herbal products have been reported $[8,9]$, such as on- and off-target effects from biologically active ingredients, side effects caused by contaminants, and herb-drug interactions. It is difficult to determine the true frequency of side effects from herbs and herbal products, since surveillance systems are much less extensive than those in place for pharmaceutical drugs. It is estimated that less than $1 \%$ of side effects or adverse events for herbal products are recorded with the current surveillance systems [10].

Some of the side effects and adverse events due to ingestion of herbs and herbal products are related to their 
action on central nervous system and can present as mood alterations, anxiety, mania, depression, hallucinations, and addictive behaviour; one example of such herbal product is ephedra, which was banned in the USA in 2004 [11].

However, psychological safety profiles of sexual enhancement products have not been characterised. This review, therefore, aimed at identifying the sexual enhancement products advertised and sold on the Internet while collecting information about their characteristics (i.e., brand names, costs, ingredients, availability, declared advantages, and disadvantages). We then focused on four substances, which are common in these products: yohimbine, maca, horny goat weed, and Ginkgo biloba, as these were reported to induce psychological side effects. We also described, less in detail, other components of sexual enhancer products that may have both somatic and psychological side effects.

\section{Methods}

A multilingual qualitative assessment of a range of websites, drug fora, and other online resources (i.e., e-commerce, enewsgroups, chat rooms, videos, e-newsletters, and bulletin boards) was carried out between February 2012 and May 2013. Exploratory qualitative searches of 203 websites in English and Italian took place using brand names through Google search engine. Of these, 106 were considered to be relevant for the study and as such were monitored on a regular basis, that is daily ( $n=21)$, weekly $(n=32)$, or monthly ( $n=$ $53)$, depending on their relevance. The remaining 97 websites were considered not to bear any interest for the present study and thus were no longer monitored. Further specific searches in the database provided by The Global Public Health Intelligence Network (GPHIN) also took place. This is a secure Internet-based early warning system that gathers preliminary reports of public health significance by monitoring global media sources near "real-time," 24 hours a day, 7 days a week basis. GPHIN is operated by the Public Health Agency of Canada and monitors news sources and websites across the globe in 9 languages (e.g., English, French, Farsi, Portuguese, Arabic, Russian, Spanish, and Chinese simplified/traditional) [12]. While a series of algorithms were used and adjusted to capture relevant information, analysis of relevant data since 2003 was also carried out manually by a multidisciplinary and multilingual team of analysts. Finally, once the active constituents of these products were identified, a comprehensive literature search was carried out using PsycInfo and Pubmed databases. Permission for the study was granted by the School of Pharmacy Ethics Committee, Hatfield, UK (15 December, 2010; PHAEC/10-42).

\section{Results}

During the website assessment stage where 136 websites were monitored for 6 months, we have identified 15 sexual enhancement products advertised and sold on the Internet. The characteristics of these products are summarized in Table 1. Yohimbe, ginseng, Ginkgo biloba, maca, horny goat weed, and L-arginine were claimed to be the most common ingredients in those products. Among all the substances identified in these products, we have found psychological safety concerns for only four: yohimbine, maca, horny goat weed, and Ginkgo biloba. Biological, pharmacological, and safety profiles of these four substances are presented below.

\subsection{Yohimbine}

3.1.1. Source and Preparations. Yohimbine is a natural tryptamine alkaloid, which can be extracted from the bark of a variety of plants mostly of African and Asian origin such as Pausinystalia yohimbe (also known as yohimbe tree) and the root of Rauvolfia serpentina. Yohimbe bark extract is traditionally used in Africa as an aphrodisiac: it has to be underlined, though, that tree bark does contain a large number of alkaloids, and yohimbine level in this natural source may be low. Yohimbine concentration has been suggested to increase in older branches [13]. A 1995 study by Betz et al. on dietary supplements containing Yohimbe extracts has shown that the yohimbine content may range from $<0.1$ to $489 \mathrm{ppm}$ compared with $7089 \mathrm{ppm}$ in the authentic material, which has been attributed to the intense dilution of final product [14]. Currently, yohimbine-containing products are advertised on the Internet not only for treating erectile dysfunction and enhancing sexual performance, but also as a fast weight-loss and body-building supplement [15-17]. Brand names include "The Millennium Male Horse Power Capsule" [18], Syntrax [15], and Xytomax (see Table 1).

3.1.2. Mechanism of Action. Yohimbine has high affinity to human alpha-2 adrenoceptors, moderate affinity to alpha1 adrenoceptors, and low affinity to some of the serotonin and dopamine receptors in the central and peripheral nervous systems [19]. Alpha-2 adrenoceptors mediate erectioninhibiting impulses in the central nervous system. Yohimbine is generally believed to enhance central sexual impulse by blocking the alpha-2 adrenoceptors in the locus coeruleus in the brain [20]. In the periphery, yohimbine has been suggested to inhibit alpha-1 and alpha-2 adrenoceptors as well as enhancing the release of nitric oxide (NO) from cavernosal endothelial cells $[21,22]$. In conclusion, the mechanism of action of yohimbine in enhancing sexual function is currently unclear.

3.1.3. Pharmacokinetics. Yohimbine hydrochloride is rapidly absorbed and the maximum plasma concentration is generally achieved in less than one hour after oral administration $[23,24]$. The mean bioavailability is low and is subject to very high variation from one individual to another [25]. The plasma concentration of yohimbine does not appear to correlate with the dose of the compound administered [26].

3.1.4. Efficacy. A meta-analysis in 1998 of seven clinical trials with yohimbine has shown a superiority of the compound over placebo in treatment of erectile dysfunction [27]. Yohimbine has also been reported to be effective in treatment of orgasmic disorders such as delayed ejaculation [28]. There have been no clinical studies testing Yohimbe bark. The Clinical Guidelines Panel on Erectile Dysfunction of the American 


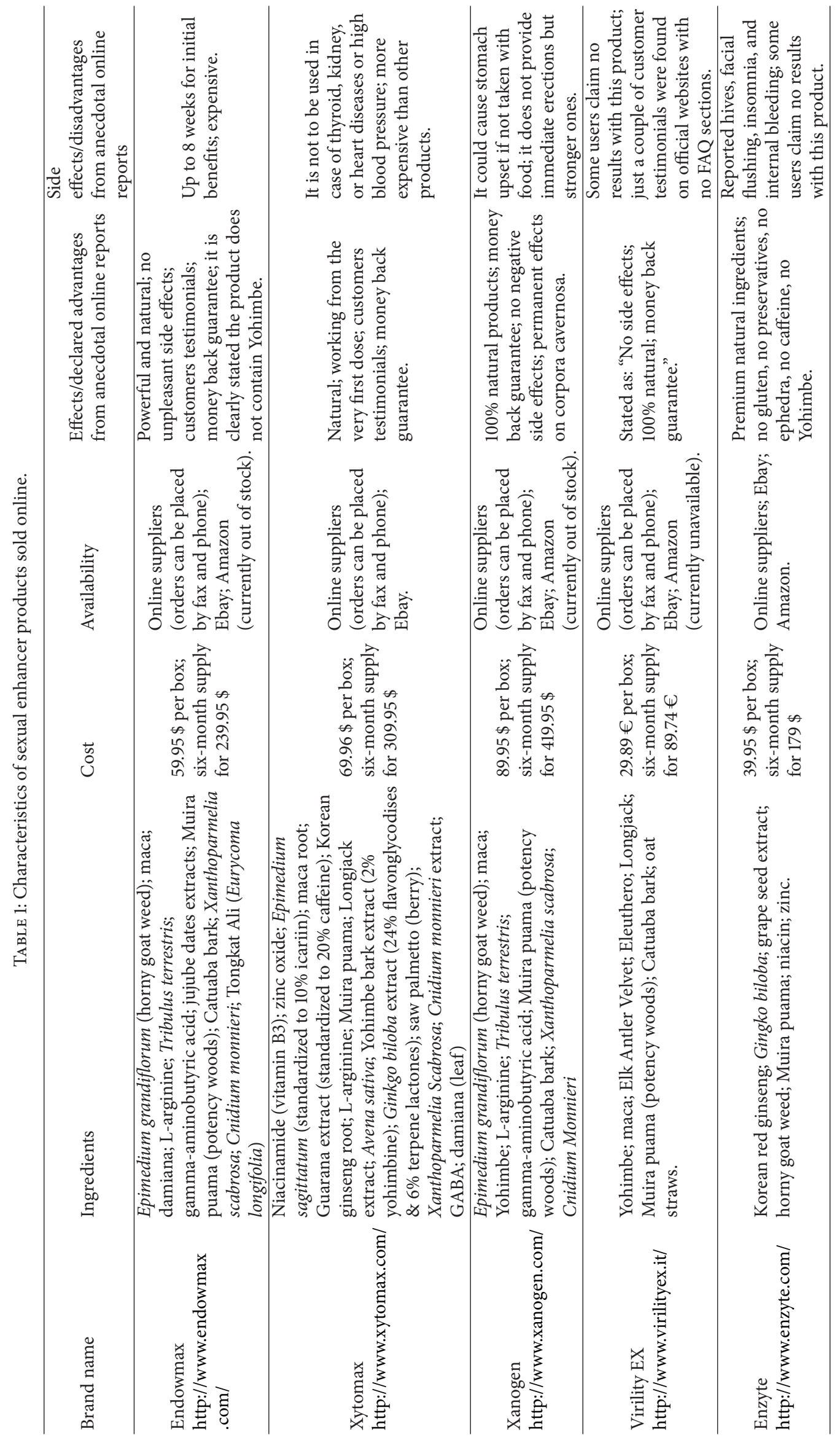




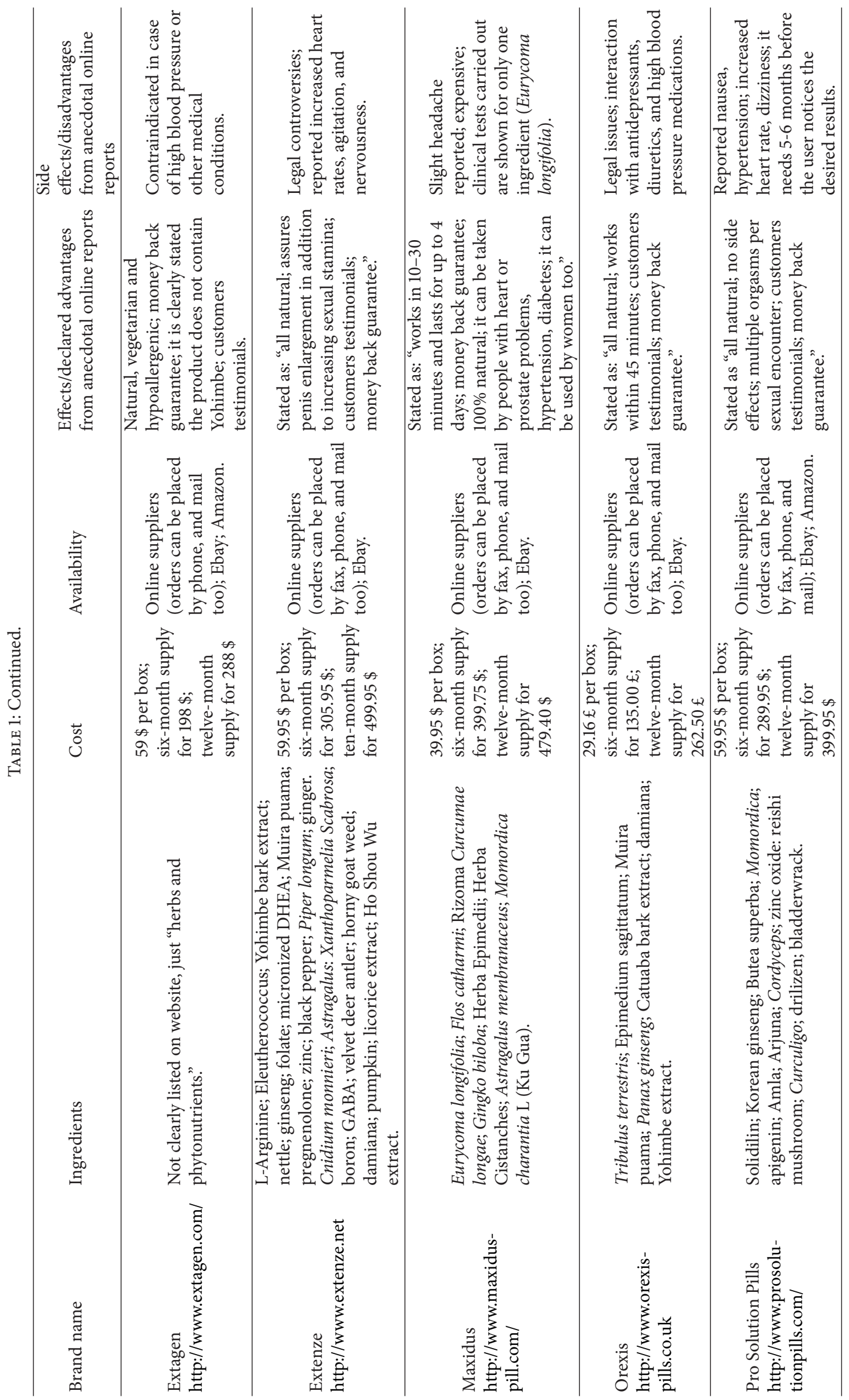




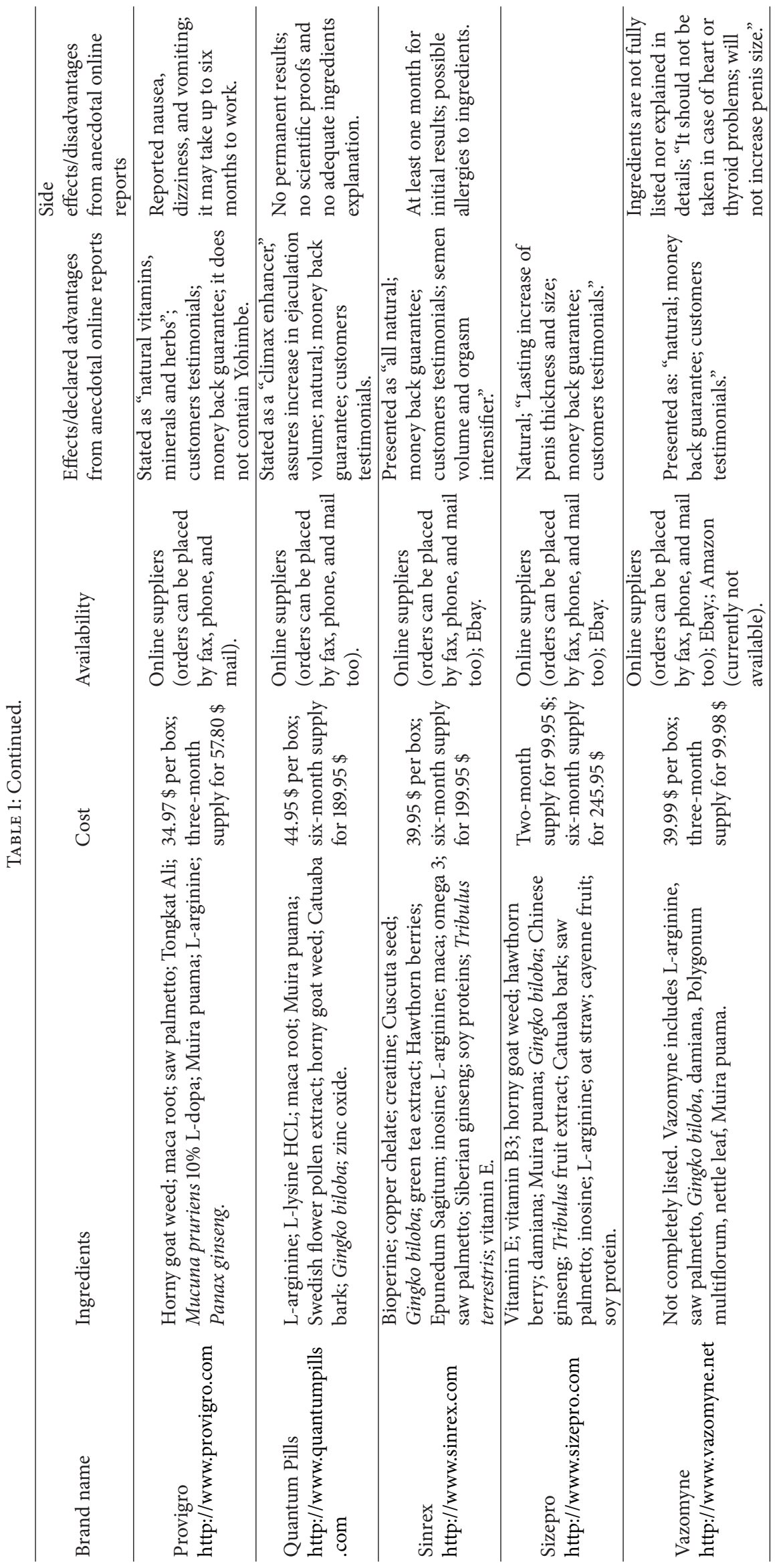


Urological Association (AUA) has concluded that the data available on Yohimbine do not allow it to be recommended as standard treatment in erectile dysfunction particularly not in organic aetiology [29]. International Society for Sexual Medicine (ISSM) Standards Committee has recently stated "if yohimbine has any potential indications for use in ED management, it would be among nonorganic ED; apart from $E D$, yohimbine has shown a limited efficacy in the treatment of premature ejaculation" [21].

3.1.5. Safety. The side effects of yohimbine include high blood pressure, increased heart rate, manic reactions, bronchospasm, palpitations, insomnia, anxiety, irritability, shivering, sweating, nausea, flushing, and headaches which all can be attributed to its central adrenergic activity $[26,30]$.

3.1.6. Case Reports Concerning Safety of Yohimbine. Adverse events mostly due to self-administration of yohimbine have been reported since 1980s. In 1993, Sandler and Aronson have described the development of progressive renal failure, cutaneous eruption, and a lupus-like syndrome in a 42-year-old Afro-American man following yohimbine use [31]. Myers has reported a case of refractory priapism in a 42-year-old HIV infected and depressed man who self-administered a product containing yohimbine to treat his erectile dysfunction and was subsequently admitted to emergency department with a 20-hour lasting erection which required insertion of a proximal corpus cavernosum to spongiosum shunt (Quackles shunt) [32]. According to California Poison Control System, 238 cases of adverse reactions after yohimbine consumption have been identified within a 7 -year period (20002006): most commonly reported adverse events have been gastrointestinal distress, tachycardia, anxiety, agitation, and hypertension [33]. US National Institute of Health also warns consumers about taking yohimbine supplements if they suffer from schizophrenia, anxiety, depression, or posttraumatic stress disorder [34]. Additional situation of emergency has been reported in Amman where the public corporation of the food and the medicine warned the citizens about the use of some unlicensed sexual stimulants, such as yohimbine, for its inclusion of poisonous substance strychnine that caused convulsions, hallucinations, and heart and kidney failure [35]. More recently, Yohimbine was detected in a product labelled as OxyELITE Pro and sold online as slimming pills. This caused the hospitalisation of two female patients aged 34 and 21 in Hong Kong for acute hepatitis symptoms. As a result, the Department of Health opened an investigation and appealed to members of the public not to buy or consume the product [30].

3.1.7. Psychological Safety. As mentioned above, anxiety and agitation are among the most common side effects of yohimbine or yohimbine-containing products [33]. US National Institute of Health warns consumers about taking yohimbine or Yohimbe supplements with some of the antidepressants and antipsychosis drugs: "People should not combine Yohimbe with monoamine oxidase (MAO) inhibitors as effects may be additive. Yohimbe should be used with caution when taken with medicines for high blood pressure, tricyclic antidepressants, or phenothiazines (a group of medicines used mostly for mental health conditions such as schizophrenia). People with kidney problems and people with psychiatric conditions should not use Yohimbe" [34]. In 1985, Linden et al. have reported a case of a 16-year-old girl who experienced an acute dissociative reaction accompanied by weakness, paraesthesia, incoordination, anxiety, headache, and chest pain after the ingestion of an aphrodisiac called "yo-yo," which has been later identified as yohimbine [36]. Acute neurotoxic effects related to the ingestion of yohimbine-containing products have been reported by Giampreti et al., who has reported the case of a 37year-old bodybuilder presented with malaise, vomiting, loss of consciousness, and repeated seizures after ingestion of $5 \mathrm{~g}$ of yohimbine during a competition [37].

\subsection{Maca}

3.2.1. Source and Preparations. Maca (Lepidium meyenii) is a Peruvian plant, which belongs to the Brassicaceae family. It grows in central Andes at more than $4000 \mathrm{~m}$ altitude; it is constituted of a flat overground portion and underground hypocotyl and roots. Hypocotyl colour allows the distinction of three different varieties: white, yellow, and black maca. Naturally dried hypocotyls have been used for centuries by native Andean populations as aphrodisiac, energizer, and enhancers of fertility and sexual function [38]. With the advent of Internet, maca has become a common ingredient of sexual enhancer products available worldwide.

3.2.2. Active Ingredients and Mechanism of Action. Maca extracts have been shown to contain benzyl glucosinolates and polyphenols, (1R,3S)-1-methyl-1,2,3,4-tetrahydro- $\beta$ carboline-3-carboxylic acid (MTCA), and p-methoxybenzyl isothiocyanate among many other chemicals [39]. The mechanism of action of maca in altering sexual behaviour is unknown.

3.2.3. Pharmacokinetics. No information could be found related to the pharmacokinetics properties of Maca.

3.2.4. Efficacy. Zheng et al. reported increased sexual behaviour in male rats and mice and decreased latency to erection in testes-removed rats following oral administration of lipid extracts of maca roots [40]. Cicero et al. demonstrated that sexual behavioural activity as well as locomotor activity was increased in rats treated with pulverised maca root orally [41]. In a further study, the same group has demonstrated that the hexanic extract of maca had more effect on sexual behaviour of rats than the methanolic and chloroformic extracts [42]. Lentz et al. measured ejaculatory and mounting behaviour and postejaculatory intervals in rats treated with maca orally for 30 days. They found that maca had only a small effect on sexual behaviour and locomotor activity but no effect on anxiety [43].

The studies with maca on human subjects were reviewed in 2010 [44]. Four randomised clinical trials met the authors' inclusion criteria: two trials suggested a significant positive 
TABLE 2: Subjective reports of forums' users about sexual enhancers side effects.

\begin{tabular}{|c|c|}
\hline \multirow{3}{*}{$\begin{array}{l}\text { Gingko } \\
\text { biloba }\end{array}$} & $\begin{array}{l}\text { (i) Head rush } \\
\text { (ii) Anxiety } \\
\text { (iii) Feeling of blood flowing through skin/feeling blood warming } \\
\text { (iv) Tinnitus } \\
\text { http://www.drugs-forum.com/forum/showthread.php?t=77902 }\end{array}$ \\
\hline & $\begin{array}{l}\text { (i) Increased heart rate } \\
\text { (ii) Dizziness } \\
\text { (iii) Chest pain } \\
\text { (iv) Phosphenes } \\
\text { http://forum.lef.org/default.aspx?f=35\&m=16405 }\end{array}$ \\
\hline & $\begin{array}{l}\text { Anxiety and nausea (Ginkgo tea consumption while assuming clomipramine) } \\
\text { http://www.socialanxietysupport.com/forum/f11/ginkgo-biloba-197737/ }\end{array}$ \\
\hline \multirow{3}{*}{ Maca } & $\begin{array}{l}\text { (i) Altered menstrual cycle (length modifications, anovulatory cycles) } \\
\text { (ii) Painful intestinal cramps } \\
\text { (iii) Severe gastritis } \\
\text { (iv) Increased blood pressure } \\
\text { (v) Moodiness } \\
\text { http://archive.tcoyf.com/forums/t/119232.aspx }\end{array}$ \\
\hline & $\begin{array}{l}\text { (i) Increased heart rate } \\
\text { (ii) Insomnia } \\
\text { (iii) Depression/anxiety } \\
\text { (iv) Worse premenstrual syndrome symptoms } \\
\text { (v) Acne breakout } \\
\text { http://www.highonhealth.org/what-nobody-tells-you-about-maca-root-powder-dangers-and-side-effects/ }\end{array}$ \\
\hline & $\begin{array}{l}\text { Mood swings } \\
\text { http://babyandbump.momtastic.com/pregnancy-tests/419834-gallery-o-tests-1075.html\#post9282851 }\end{array}$ \\
\hline $\begin{array}{l}\text { Horny } \\
\text { goat weed }\end{array}$ & $\begin{array}{l}\text { (i) Fever } \\
\text { (ii) Increased heart rate } \\
\text { (iii) Aggressiveness } \\
\text { (iv) Irritability } \\
\text { http://www.muscleandstrength.com/supplements/ingredients/horny-goat-weed.html\#5 }\end{array}$ \\
\hline
\end{tabular}

effect of maca on sexual dysfunction or sexual desire in healthy postmenopausal women [45] or healthy adult men [46], while the other trial failed to show any effects on healthy cyclists [47]. A further trial assessed the effects of maca in patients with erectile dysfunction using the International Index of Erectile Function Questionnaire and showed significant effects [48]. Lee et al. have reviewed the literature to determine maca's possible effects on menopausal symptoms and confirmed the inadequacy of the present data to clearly state efficacy and safety [49]. An overview of systematic reviews on various complementary medicine products for sexual dysfunction in elderly patients has found that the evidence for maca was insufficient [50].

3.2.5. Safety. Piacente et al. (2002) have shown the existence of 1R,3S-1-methyl-1,2,3,4-tetrahydro- $\beta$-carboline3 -carboxylic acid (MTCA) in the extracts of maca. MTCA has been suggested to be an inhibitor of the monoamine oxidase (MAO) enzyme and is a comutagenic or a precursor to mutagenic compounds [51]. Because of these potential mutagenic properties of MTCA, the French Agency for Sanitary Security warned consumers of powdered maca root about possible health risks from its ingestion [52]. These findings have been disputed by others based on the assumption that MTCA is deactivated during the boiling process of the maca roots [53]. MTCA-like compounds have also been suggested to be associated with craving behaviour, which is common in addictions [51]. Side effects subjectively reported by fora users were altered menstrual cycles, moodiness, cramps, gastritis, and insomnia (see Table 2).

\subsection{Horny Goat Weed}

3.3.1. Source and Preparations. Epimedium is a genus of plants of the Berberidaceae family, including more than 50 species. Among the most frequently used in sexual enhancer products are Epimedium grandiflorum and Epimedium sagittatum. Epimedium grandiflorum is commonly known as horny goat weed named after the legendary discovery of its aphrodisiac properties, attributed to a Chinese goat herder who noticed an increased sexual activity in his herd after they ate the plant's leaves [54], and sold online with various names including ViaXtreme, which also contains undeclared sildenafil [17].

3.3.2. Active Ingredients and Mechanism of Action. The active ingredient of horny goat weed has been suggested to be 
icariin, a flavonol glycoside [55]. Icariin and its derivatives have been suggested to increase NO synthesis in the penis [56], inhibit PDE5 in cavernosal smooth muscle [57-59], have positive neurotrophic effect on nitrergic nerves [56], enhance smooth muscle proliferation [60], and decrease advanced glycation endproduct formation [60] and mimic endogenous androgens [61]. Icariin has also been suggested to have antiinflammatory, antiosteoporotic, and neuroprotective properties [62-64].

3.3.3. Pharmacokinetics. Icariin has been shown to have low oral bioavailability, poor absorption, and short plasma halflife [65]. Because of these unfavourable pharmacokinetics profiles, liposome encapsulated formulations of icariin are being developed [66].

3.3.4. Efficacy. Although icariin has been shown to be efficacious in treatment of erectile dysfunction in aged [67], diabetic [68], and castrated [69] animal models, it has not been tested in any randomised clinical trial.

3.3.5. Safety. No long-term toxicity study has been conducted using horny goat weed (or icariin) in any animal species. Partin and Pushkin have presented a case of a 66-year-old man with a history of cardiovascular disease who, after two weeks of consumption of herbal sexual enhancer containing horny goat weed, was admitted to hospital with a newonset tachyarrhythmia and hypomanic symptoms (sexual and verbal inappropriate behaviour, irritable mood, and hyperverbal speech). The patient needed to undergo an electric cardioversion and to be treated with a therapy based on olanzapine and lorazepam [70]. Metz et al. reported a case of a painful vasculitic rash in a 77-year-old man, who had started a treatment with Ginkgo biloba and horny goat weed tablets four days before. The man improved after three days as an inpatient, with the suspension of the herbal supplement [71].

3.3.6. Psychological Safety. As mentioned above, one case has been reported with hypomanic symptoms combined with tachyarrhythmia [70]. During the online monitoring of discussion fora, several cases of aggressive behaviour and irritability were noted (see Table 2 ).

\subsection{Ginkgo biloba}

3.4.1. Source and Preparations. Ginkgo biloba is a living fossil tree, belonging to Ginkgoaceae family. Typically grown in China, Ginkgo plants are tall, normally reaching $20-35 \mathrm{~m}$ of height, with fan-shaped leaves. The extracts obtained from Ginkgo leaves contain flavonoid glycosides (e.g., myricetin and quercetin) and terpenoids (e.g., ginkgolides and bilobalides) and have been used for centuries in traditional Chinese medicine, particularly for memory enhancement and blood flow improvement.

3.4.2. Active Ingredients and Mechanism of Action. The most commonly used Ginkgo biloba extract is EGb761, which contains flavonoid glycosides, mainly composed of kaempferol, quercetin glucorhamnoside esters, and terpenes of ginkgolides and bilobalides. These ingredients have been suggested to have the ability to inhibit MAO enzyme and uptake of certain neurotransmitters such as noradrenaline and serotonin in the central nervous system [72]. A recent meta-analysis of 28 clinical studies with Ginkgo has found no significant effect on cognitive function [73]. Ginkgo extracts have been suggested to improve sexual function by improving the blood flow to the brain as well as to the genital organs. These extracts have also been suggested to increase NO bioavailability, which may have positive impact on sexual function [74].

3.4.3. Pharmacokinetics. Extracts of Ginkgo are a mixture of substances with a wide variety of physical and chemical properties and activities. A recent review on the pharmacokinetic properties of these substances concluded that the available pharmacokinetic data are rare and more studies need to be conducted [75]. It is generally accepted that Ginkgo extract is well absorbed in humans, rats, and rabbits after oral administration [75].

3.4.4. Efficacy. Ginkgo extracts have been tested as a treatment for antidepressant-induced sexual dysfunction, which is a common side effect in depressive disorder therapy, especially when using selective serotonin reuptake inhibitors (SSRIs). Despite the initial positive effect on sexual function based on various case reports [76], two randomised placebo controlled trials have found no significant benefit on sexual function with Ginkgo extracts [77, 78]. Although Ginkgo extracts have been suggested for the treatment of female sexual arousal disorders [79], no placebo controlled randomised trial has been reported.

3.4.5. Safety. A recent long-term study by National Toxicology Program has demonstrated that oral administration of Ginkgo extract caused cancer of thyroid gland and liver, atrophy of the olfactory epithelium, nephropathy, and mononuclear cell leukaemia in rats and mice [80]. One of the major ingredients, quercetin, is a known mutagen [81]. In reviews of the efficacy and safety of Ginkgo extracts in human subjects, no serious side effects were reported in clinical trials and side effects were similar to those seen in the placebo groups [82]. Ginkgo extract has been suggested to affect platelet aggregation, which may not only be useful in prevention of pathological events as thrombosis, but may also cause spontaneous bleeding in healthy individuals or patients treated with anticoagulants such as warfarin and aspirin [83]. There have been case reports of subdural hematoma or cerebral haemorrhage with headache, confusion, blurred vision, nausea, and vomiting after Ginkgo administration [84]. Some Ginkgo extracts may contain $4^{\prime}$-O-methylpyridoxine, which is a neurotoxin also known as "ginkgotoxin." Ginkgotoxin poisoning is characterised by epileptic convulsions, vomiting, unconsciousness, and irritability, which may be fatal if not promptly treated [85]. 
3.4.6. Psychological Safety. Ginkgo may interact with other medications particularly those acting on the central nervous system. It may decrease (alprazolam, citalopram, and diazepam) or increase (clozapine, methadone, olanzapine, and fluvoxamine) effects and side effects of such drugs; it may also induce hypomanic symptoms when taken together with St. John's wort, fluoxetine, and melatonin [86]. Anxiety was the most common psychological effect reported by Ginkgo users at Internet discussion fora (see Table 2).

3.5. Other Substances. Velvet antler has been used in traditional Chinese medicine for centuries, mainly as an energizer and to treat joint pain, cardiovascular diseases, and impotence. The name refers to the velvety skin covering growing antlers of male elk, deer, and moose, which can be removed with no harm for the animal. In western countries, elks and deer are anesthetized with xylazine or lidocaine before having velvet removed; this practice had determined an ethical controversy among veterinarians, to find balance between animal welfare and food safety (not being known drugs' withdrawal time for velvet) [87]. The most relevant issue currently identified for elk or deer velvet antler consumption is related to an infectious neurodegenerative prion disease known as chronic wasting disease (CWS). The core symptoms of this encephalopathy are notable weight loss and behavioural abnormalities (e.g., progressive hyperexcitability) [88]. Though currently interspecies transmission has not been yet demonstrated, the presence of CWS prions in animal muscle, fat, glands, and antler velvet may expose humans to infection by handling or consumption of diseased cervids products $[89,90]$. No psychoactive properties have been yet demonstrated for velvet antler.

Turnera diffusa, also known as "damiana," is a small shrub common in Mexico, Central and South America, and the Caribbean. Turnera diffusa leaf is traditionally thought to be stimulant, aphrodisiac, tonic, diuretic, laxative, and useful to treat menstrual and pregnancy disorders [91]. Aphrodisiac and psychoactive properties have been ascribed for centuries to damiana. Its leaves are usually boiled to make an infusion with the aim of intensifying sexual sensations; moreover, when smoked, damiana leaves may produce similar effects to marijuana [92]. It has recently been found in products advertised on the Internet to increase sensuality, especially among women [16], as legal and safer alternative to Cannabis and sold as "mystical incenses" [93, 94]. These also often contain synthetic cannabinoids such as JWH-18, JWH-73, and HU210 that may cause severe intoxication and death $[95,96]$.

Nymphaea caerulea is a lotus flower belonging to Nymphaeaceae family. It is also known as "Blue Water Lily" or "Egyptian Lotus" and it is sold as a powder named "Blue Lotus." The flower has been used by ancient Egyptians not only to enhance sex drive and to improve sexual performance, but also to stimulate blood flow and as an antiageing treatment. It has also recreational potential when added to wine or smoked, due to its psychoactive properties [97]. The flower may indeed induce both narcotic and euphoric effects and, if taken in large amounts, may cause slightly hallucinogenic symptoms [98].
Ptychopetalum olacoides (Muira puama), also called "potency wood," grows primarily in Brazil. Popular belief claims that it can improve sexual function especially in old men [7]. This herb may be found in plant markets or in herbal formulations, usually sold to increase physical, mental, and/or sexual performance. Few clinical studies have so far examined the prosexual effects of Muira puama. Waynberg reported in 1994 that $60 \%$ of men with low libido have reported increased sexual desire and $50 \%$ of men with poor erection have reported improved erectile function following Muira puama administration [99]. Another study has shown that Muira puama improved sexual desire, sexual fantasies, and the ability to achieve orgasm in $65 \%$ of women with prior sexual dysfunction [100].

3.5.1. Synthetic Substances. Among synthetic substances used as sexual enhancers, well-known examples include MDPV (methylenedioxypyrovalerone), known as "Ivory Wave," 2C$\mathrm{B}$, and mephedrone (4-methylmethcathinone), also called with the nickname of "Miaow Miaow." The aforementioned substances have stimulating and aphrodisiac properties similar to amphetamines and MDMA ("Ecstasy"). Because of their partially synthetic and partially natural composition, some sexual enhancer substances are defined "mixed." Lust is a stimulant made up of Sida cordifolia extract. This plant contains L-ephedrine, which is a natural amphetamine acting on both central and peripheral nervous systems. The effects of L-ephedrine are mainly linked to an expansion of sexual perception [101]. Another component of Lust is saw palmetto (Serenoa repens, Serenoa serrulata), another natural aphrodisiac; the plant's berries are used to increase muscular power and libido. The last Lust component is L-arginine, an amino acid believed to have positive effects on impotence and infertility [102].

\section{Discussion and Conclusions}

The exponential increase in the use of unlicensed sexual enhancing products, often characterized by the undeclared presence of psychoactive agents, represents a serious challenge both from clinical and public health point of view, despite their large and uncontrolled distribution on the Internet, including e-commerce websites (Ebay, Amazon). It has been estimated that approximately six million men in the EU purchase these products from the Internet [103]. Possible reasons behind such a risky behaviour include (a) the embarrassment to speak with a doctor, (b) the thought that buying them online would be the fastest and cheapest way to solve the problem, (c) curiosity, (d) peer-pressure, and (e) the increase of sexual confidence and performance [5].

In a performance-based society, the e-commerce of food and herbal supplements sold for sexual enhancing purposes is becoming a highly profitable market as a result of lowcost manufacturing capacity in countries such as China and India as well as the globalization of free trade and the Internet as a platform for rapid distribution [94, 103, 104]. In this context, unscrupulous manufacturers/retailers are exploiting 
the common belief that "natural" products are healthier alternatives to pharmaceutical treatments and infiltrate undeclared harmful psychoactive substances in their products [5]. This represents a growing public health threat, which is putting the population at risk. The frequent occurrence of side effects and the potential induction of symptoms of psychiatric interest, such as mood elevation, anxiety, hallucinations, and other psychotic symptoms, are issues that need to be clarified and constantly monitored at the international level $[105,106]$. The possible impact on subjects with psychiatric disorders, usually at risk for sexual disjunctions and therefore possible consumers, may be devastating.

Sexual function is closely related to the function of the central nervous system; it is therefore not surprising that psychological and psychiatric disorders are closely associated with sexual dysfunction [107]. For example, depression can be a cause or result of erectile dysfunction. Some of the antidepressants can also cause sexual dysfunction. It is therefore essential that patients with sexual dysfunction either of psychogenic or organic aetiology should avoid taking such herbal products which may have adverse effects on their mental state. Similarly, patients taking centrally acting medications such as antidepressants or antipsychotics should avoid using such products which may cause unwanted herbdrug interactions and hence side effects, one of which may be sexual dysfunction.

In addition, there is still a distinct paucity of evidencebased and up-to-date information available for medical professionals on the effects and risks associated with the consumption of these products. In this sense, the use of unstructured, free, and near real-time sources of information such as Internet news and online reports is essential to rapidly acquire and share knowledge and understanding of the rapidly changing drug market and be better prepared to face this new challenge globally.

A limitation of this study was that only publicly available websites and similar sources were monitored. In order to improve the coverage of the study, not only the websites but also more private ways of communication (including newsgroups, chat rooms, mailing lists, social networking, enewsletters, bulletin boards, and videos) were monitored. Because some of the discussion fora have restricted access to non-registered members, a comprehensive quantitative analysis could not always be fully performed. A further limitation may be that the present findings do rely mostly on what is reported by users. We did not have any possibility to ascertain whether the substance the online alleged drug users were taking was only a sexual stimulant or a combination of various products.

Considering the fact that only less than $1 \%$ of the side effects are reported for herbal products, it is concerning to find the variety of psychological symptoms disclosed by the users in online discussion fora, which may only be a fraction of the tip of an iceberg. In conclusion, the four substances, yohimbine, maca, horny goat weed, and Ginkgo biloba, commonly found in sexual enhancement products carry potential safety risks particularly in psychological context. The users, physicians, and regulators should be aware of these risks.

\section{Conflict of Interests}

The authors declare that there is no conflict of interests regarding the publication of this paper.

\section{Acknowledgments}

Authors would like to acknowledge the contribution of the Public Health Agency of Canada and the World Health Organization (WHO) for granting access to the GPHIN database as well as the Canadian Centre on Substance Abuse (CCSA).

\section{References}

[1] S. A. Pratap and S. Rajender, "Potent natural aphrodisiacs for the management of erectile dysfunction and male sexual debilities," Frontiers in Bioscience, vol. 4, pp. 167-180, 2012.

[2] N. Campbell, J. P. Clark, V. J. Stecher et al., "Adulteration of purported herbal and natural sexual performance enhancement dietary supplements with synthetic phosphodiesterase type 5 inhibitors," Journal of Sexual Medicine, vol. 10, no. 7, pp. 18421849, 2013.

[3] S. L. Kenyon, J. Button, P. Perella, D. A. McKeown, and D. W. Holt, "An herbal remedy for impotence: more than was bargained for," Journal of Clinical Pharmacology, vol. 46, no. 11, pp. 1379-1381, 2006.

[4] B. J. Venhuis, M. E. Zwaagstra, J. D. J. van den Berg et al., Illicit Erectile Dysfunction Products in the Netherlands. A Decade of Trends and a 2007-2010 Product Update, National Institute for Public Health and the Environment, 2011.

[5] M. Evans-Brown, J. McVeigh, C. Perkins, and M. A. Bellis, Human Enhancement Drugs: The Emerging Challenges to Public Health, North West Public Health Observatory, 2012.

[6] S. Balayssac, V. Gilard, C. Zedde, R. Martino, and M. MaletMartino, "Analysis of herbal dietary supplements for sexual performance enhancement: first characterization of propoxyphenyl-thiohydroxyhomosildenafil and identification of sildenafil, thiosildenafil, phentolamine and tetrahydropalmatine as adulterants," Journal of Pharmaceutical and Biomedical Analysis, vol. 63, pp. 135-150, 2012.

[7] R. Shamloul, "Natural aphrodisiacs," Journal of Sexual Medicine, vol. 7, no. 1, pp. 39-49, 2010.

[8] E. Ernst, "Harmless herbs? A review of the recent literature," The American Journal of Medicine, vol. 104, no. 2, pp. 170-178, 1998.

[9] S. Bent and R. Ko, "Commonly used herbal medicines in the United States: a review," The American Journal of Medicine, vol. 116, no. 7, pp. 478-485, 2004.

[10] Adverse event reporting for dietary supplements: An inadequate safety valve. OEI-01-00-00180. Office of the Inspector General, HHS, 2001. 2001.

[11] P. G. Shekelle, M. L. Hardy, S. C. Morton et al., "Efficacy and safety of ephedra and ephedrine for weight loss and athletic performance: a meta-analysis," Journal of the American Medical Association, vol. 289, no. 12, pp. 1537-1545, 2003.

[12] M. Keller, M. Blench, H. Tolentino et al., "Use of unstructured event-based reports for global infectious disease surveillance," Emerging Infectious Diseases, vol. 15, no. 5, pp. 689-695, 2009.

[13] W. Blaschek, S. Ebel, E. Hackenthal et al., Hagers Handbuch der Drogen und Arzneistoffe, Springer, Heidelberg, Germany, 2007. 
[14] J. M. Betz, K. D. White, and A. H. der Marderosian, "Gas chromatographic determination of yohimbine in commercial yohimbe products," Journal of AOAC International, vol. 78, no. 5, pp. 1189-1194, 1995.

[15] GPHIN, Syntrax contains the female qualm of sexual impotence medicine weight loss looking at acute disease, Communication from Hong Kong, 2009.

[16] GPHIN, Again feel the woman! Communication posted on 2012/05/15 from Russia, 2012

[17] GPHIN, FDA warns on sex, diet pills, communication posted on 2012/03/07 from South Florida Sun-Sentine, United States, 2012.

[18] GPHIN, Open once strong medicine contains hazardous wastes. The bureau appeals to sanitary science to stop use, Singapore, 2010.

[19] M. R. Goldberg and D. Robertson, "Yohimbine: a pharmacological probe for study of the $\alpha 2$-adrenoreceptor," Pharmacological Reviews, vol. 35, no. 3, pp. 143-180, 1983.

[20] A. Y. W. Chang, C.-M. Huang, J. Y. H. Chan, and S. H. $\mathrm{H}$. Chan, "Involvement of noradrenergic innervation from locus coeruleus to hippocampal formation in negative feedback regulation of penile erection in the rat," Hippocampus, vol. 11, no. 6, pp. 783-792, 2001.

[21] H. Porst, A. Burnett, G. Brock et al., "SOP conservative (Medical and Mechanical) treatment of erectile dysfunction," Journal of Sexual Medicine, vol. 10, no. 1, pp. 130-171, 2013.

[22] U. Simonsen, D. Prieto, M. Hernández, I. Sáenz De Tejada, and A. García-Sacristán, "Prejunctional $\alpha 2$-adrenoceptors inhibit nitrergic neurotransmission in horse penile resistance arteries," Journal of Urology, vol. 157, no. 6, pp. 2356-2360, 1997.

[23] J. A. Owen, S. L. Nakatsu, J. Fenemore, M. Condra, D. H. C. Surridge, and A. Morales, "The pharmacokinetics of yohimbine in man," European Journal of Clinical Pharmacology, vol. 32, no. 6, pp. 577-582, 1987.

[24] S. W. Tam, M. Worcel, and M. Wyllie, "Yohimbine: a clinical review," Pharmacology and Therapeutics, vol. 91, no. 3, pp. 215243,2001

[25] S. K. Guthrie, M. Hariharan, and L. J. Grunhaus, "Yohimbine bioavailability in humans," European Journal of Clinical Pharmacology, vol. 39, no. 4, pp. 409-411, 1990.

[26] Federal Institute for Risk Assessment, 2013, http://ec.europa.eu/ food/food/labellingnutrition/vitamins/sa_yohimbe_en.pdf.

[27] E. Ernst and M. H. Pittler, "Yohimbine for erectile dysfunction: a systematic review and meta-analysis of randomized clinical trials," Journal of Urology, vol. 159, no. 2, pp. 433-436, 1998.

[28] A. A. Adeniyi, G. S. Brindley, J. P. Pryor, and D. J. Ralph, "Yohimbine in the treatment of orgasmic dysfunction," Asian Journal of Andrology, vol. 9, no. 3, pp. 403-407, 2007.

[29] D. K. Montague, J. P. Jarow, G. A. Broderick et al., "Chapter 1: the management of erectile dysfunction: an AUA update," The Journal of Urology, vol. 174, no. 1, pp. 230-239, 2005.

[30] GPHIN, Public urged not to buy or use slimming products with undeclared and banned drug ingredients, communication posted on 2013/06/05 from Hong Kong Government, 2013.

[31] B. Sandler and P. Aronson, "Yohimbine-induced cutaneous drug eruption, progressive renal failure, and lupus-like syndrome," Urology, vol. 41, no. 4, pp. 343-345, 1993.

[32] A. Myers and F. Barrueto Jr., "Refractory priapism associated with ingestion of yohimbe extract," Journal of Medical Toxicology, vol. 5, no. 4, pp. 223-225, 2009.
[33] T. Kearney, N. Tu, and C. Haller, "Adverse drug events associated with yohimbine-containing products: a retrospective review of the California poison control system reported cases," Annals of Pharmacotherapy, vol. 44, no. 6, pp. 1022-1029, 2010.

[34] "National Center for Complementary and Alternative Medicine. Herbs at a glance: Yohimbe. [Internet]," 2007, http:// nccam.nih.gov/health/yohimbe.

[35] GPHIN, Warning on of the use of sexual stimulants that contains a poisonous substance, communication posted on 2008/07/29 from Jordan (in Arabic), 2008.

[36] C. H. Linden, W. P. Vellman, and B. Rumack, "Yohimbine: a new street drug," Annals of Emergency Medicine, vol. 14, no. 10, pp. 1002-1004, 1985.

[37] A. Giampreti, D. Lonati, C. Locatelli, L. Rocchi, and M. T. Campailla, "Acute neurotoxicity after yohimbine ingestion by a body builder," Clinical Toxicology, vol. 47, no. 8, pp. 827-829, 2009.

[38] G. F. Gonzales, "Ethnobiology and ethnopharmacology of Lepidium meyenii (Maca), a plant from the peruvian highlands," Evidence-Based Complementary and Alternative Medicine, vol. 2012, Article ID 193496, 10 pages, 2012.

[39] C. Clément, D. A. Diazgrados, B. Avula et al., "Influence of colour type and previous cultivation on secondary metabolites in hypocotyls and leaves of maca (Lepidium meyenii Walpers)," Journal of the Science of Food and Agriculture, vol. 90, no. 5, pp. 861-869, 2010.

[40] B. L. Zheng, K. He, C. H. Kim et al., "Effect of a lipidic extract from Lepidium meyenii on sexual behavior in mice and rats," Urology, vol. 55, no. 4, pp. 598-602, 2000.

[41] A. F. G. Cicero, E. Bandieri, and R. Arletti, "Lepidium meyenii Walp. improves sexual behaviour in male rats independently from its action on spontaneous locomotor activity," Journal of Ethnopharmacology, vol. 75, no. 2-3, pp. 225-229, 2001.

[42] A. F. G. Cicero, S. Piacente, A. Plaza, E. Sala, R. Arletti, and C. Pizza, "Hexanic Maca extract improves rat sexual performance more effectively than methanolic and chloroformic Maca extracts," Andrologia, vol. 34, no. 3, pp. 177-179, 2002.

[43] A. Lentz, K. Gravitt, C. C. Carson, L. Marson, and F. Giuliano, "Acute and chronic dosing of Lepidium meyenii (Maca) on male rat sexual behavior," Journal of Sexual Medicine, vol. 4, no. 2, pp. 332-340, 2007.

[44] B.-C. Shin, M. S. Lee, E. J. Yang, H.-S. Lim, and E. Ernst, "Maca (L. meyenii) for improving sexual function: a systematic review," BMC Complementary and Alternative Medicine, vol. 10, article 44, 2010.

[45] N. A. Brooks, G. Wilcox, K. Z. Walker, J. F. Ashton, M. B. Cox, and L. Stojanovska, "Beneficial effects of Lepidium meyenii (Maca) on psychological symptoms and measures of sexual dysfunction in postmenopausal women are not related to estrogen or androgen content," Menopause, vol. 15, no. 6, pp. 1157-1162, 2008.

[46] G. F. Gonzales, A. Córdova, K. Vega et al., "Effect of Lepidium meyenii (MACA) on sexual desire and its absent relationship with serum testosterone levels in adult healthy men," Andrologia, vol. 34, no. 6, pp. 367-372, 2002.

[47] M. Stone, A. Ibarra, M. Roller, A. Zangara, and E. Stevenson, "A pilot investigation into the effect of maca supplementation on physical activity and sexual desire in sportsmen," Journal of Ethnopharmacology, vol. 126, no. 3, pp. 574-576, 2009.

[48] T. Zenico, A. F. G. Cicero, L. Valmorri, M. Mercuriali, and E. Bercovich, "Subjective effects of Lepidium meyenii (Maca) 
extract on well-being and sexual performances in patients with mild erectile dysfunction: a randomised, double-blind clinical trial," Andrologia, vol. 41, no. 2, pp. 95-99, 2009.

[49] M. S. Lee, B.-C. Shin, E. J. Yang, H.-J. Lim, and E. Ernst, "Maca (Lepidium meyenii) for treatment of menopausal symptoms: a systematic review," Maturitas, vol. 70, no. 3, pp. 227-233, 2011.

[50] E. Ernst, P. Posadzki, and M. S. Lee, "Complementary and alternative medicine (CAM) for sexual dysfunction and erectile dysfunction in older men and women: an overview of systematic reviews," Maturitas, vol. 70, no. 1, pp. 37-41, 2011.

[51] S. Piacente, V. Carbone, A. Plaza, A. Zampelli, and C. Pizza, "Investigation of the tuber constituents of maca (Lepidium meyenii Walp.)," Journal of Agricultural and Food Chemistry, vol. 50, no. 20, pp. 5621-5625, 2002.

[52] APSSA, "From the French Agency of Sanitary Security on foods relative to the risk assessment for health by consuming pulverized maca roots or as alimentary supplement," AfssaSaisine 2004-SA-0155, 2004.

[53] G. F. Gonzales and C. Gonzales-Castañeda, "The methyltetrahydro- $\beta$-carbolines in Maca (Lepidium meyenii)," EvidenceBased Complementary and Alternative Medicine, vol. 6, no. 3, pp. 315-316, 2009.

[54] Horny Goats Weed [Internet] 2013, http://www.herbwisdom .com/herb-horny-goats-weed.html.

[55] J. J. Liu, S. P. Li, and Y. T. Wang, "Optimization for quantitative determination of four flavonoids in Epimedium by capillary zone electrophoresis coupled with diode array detection using central composite design," Journal of Chromatography A, vol. 1103, no. 2, pp. 344-349, 2006.

[56] A. W. Shindel, Z.-C. Xin, G. Lin et al., "Erectogenic and neurotrophic effects of icariin, a purified extract of horny goat weed (Epimedium spp.) in vitro and in vivo," Journal of Sexual Medicine, vol. 7, no. 4, pp. 1518-1528, 2010.

[57] Z.-C. Xin, E. K. Kim, C. S. Lin et al., "Effects of icariin on cGMP-specific PDE5 and cAMP-specific PDE4 activities," Asian Journal of Andrology, vol. 5, no. 1, pp. 15-18, 2003.

[58] Z. Jiang, B. Hu, J. Wang et al., "Effect of icariin on cyclic GMP levels and on the mRNA expression of cGMP-binding cGMPspecific phosphodiesterase (PDE5) in penile cavernosum," Journal of Huazhong University of Science and Technology, vol. 26, no. 4, pp. 460-462, 2006.

[59] H. Ning, Z.-C. Xin, G. Lin, L. Banie, T. F. Lue, and C.-S. Lin, "Effects of icariin on phosphodiesterase-5 activity in vitro and cyclic guanosine monophosphate level in cavernous smooth muscle cells," Urology, vol. 68, no. 6, pp. 1350-1354, 2006.

[60] J. Zhang, A.-M. Li, B.-X. Liu et al., "Effect of icarisid II on diabetic rats with erectile dysfunction and its potential mechanism via assessment of AGEs, autophagy, mTOR and the NO-cGMP pathway," Asian Journal of Andrology, vol. 15, no. 1, pp. 143-148, 2013.

[61] Z.-B. Zhang and Q.-T. Yang, "The testosterone mimetic properties of icariin," Asian Journal of Andrology, vol. 8, no. 5, pp. 601-605, 2006.

[62] B. Liu, H. Zhang, C. Xu et al., "Neuroprotective effects of icariin on corticosterone-induced apoptosis in primary cultured rat hippocampal neurons," Brain Research, vol. 1375, pp. 59-67, 2011.

[63] C. Shao-Rui, X. Xiang-Zhen, W. Yu-Hua et al., "Icariin derivative inhibits inflammation through suppression of p38 mitogenactivated protein kinase and nuclear factor- $\kappa$ b pathways," Biological and Pharmaceutical Bulletin, vol. 33, no. 8, pp. 1307-1313, 2010.
[64] R. Feng, L. Feng, Z. Yuan et al., "Icariin protects against glucocorticoid-induced osteoporosis in vitro and prevents glucocorticoid-induced osteocyte apoptosis in vivo," Cell Biochemistry and Biophysics, vol. 67, no. 1, pp. 189-197, 2013.

[65] L. Ye, J. Chen, and S. Liu, "Pharmacokinetics of icariin in rats," Chinese Pharmaceutical Journal, vol. 34, no. 1, pp. 33-36, 1999.

[66] W. Yang, X. C. Yu, X. Y. Chen, L. Zhang, C. T. Lu, and Y. Z. Zhao, "Pharmacokinetics and tissue distribution profile of icariin propylene glycol-liposome intraperitoneal injection in mice," Journal of Pharmacology and Pharmacotherapeutics, vol. 64, no. 2, pp. 190-198, 2012.

[67] M. N. Makarova, O. N. Pozharitskaya, A. N. Shikov, S. V. Tesakova, V. G. Makarov, and V. P. Tikhonov, "Effect of lipidbased suspension of Epimedium koreanum Nakai extract on sexual behavior in rats," Journal of Ethnopharmacology, vol. 114, no. 3, pp. 412-416, 2007.

[68] T. Liu, H. Xin, W.-R. Li et al., "Effects of icariin on improving erectile function in streptozotocin-induced diabetic rats," Journal of Sexual Medicine, vol. 8, no. 10, pp. 2761-2772, 2011.

[69] W.-J. Liu, Z.-C. Xin, H. Xin, Y.-M. Yuan, L. Tian, and Y.-L. Guo, "Effects of icariin on erectile function and expression of nitric oxide synthase isoforms in castrated rats," Asian Journal of Andrology, vol. 7, no. 4, pp. 381-388, 2005.

[70] J. F. Partin and Y. R. Pushkin, "Tachyarrhythmia and hypomania with horny goat weed," Psychosomatics, vol. 45, no. 6, pp. 536537, 2004.

[71] D. Metz, P. Weston, and D. Barker, "Case report of vasculitic rash induced by Ginkgo biloba and/or Horny Goat Weed," BMJ Case Reports, vol. 2009, Article ID bcr07.2008.0399, 2009.

[72] C. J. Fehske, K. Leuner, and W. E. Müller, "Ginkgo biloba extract (EGb761) influences monoaminergic neurotransmission via inhibition of NE uptake, but not MAO activity after chronic treatment," Pharmacological Research, vol. 60, no. 1, pp. 68-73, 2009.

[73] K. R. Laws, H. Sweetnam, and T. K. Kondel, "Is Ginkgo biloba a cognitive enhancer in healthy individuals? A meta-analysis," Human Psychopharmacology, vol. 27, no. 6, pp. 527-533, 2012.

[74] C. A. Schmitt and V. M. Dirsch, "Modulation of endothelial nitric oxide by plant-derived products," Nitric Oxide-Biology and Chemistry, vol. 21, no. 2, pp. 77-91, 2009.

[75] C. Ude, M. Schubert-Zsilavecz, and M. Wurglics, "Ginkgo biloba extracts: a review of the pharmacokinetics of the active ingredients," Clinical Pharmacokinetics, vol. 52, no. 9, pp. 727749, 2013.

[76] D. MacKay, "Nutrients and botanicals for erectile dysfunction: examining the evidence," Alternative Medicine Review, vol. 9, no. 1, pp. 4-16, 2004.

[77] B.-J. Kang, S.-J. Lee, M.-D. Kim, and M.-J. Cho, "A placebocontrolled, double-blind trial of Ginkgo biloba for antidepressant-induced sexual dysfunction," Human Psychopharmacology, vol. 17, no. 6, pp. 279-284, 2002.

[78] D. Wheatley, "Triple-blind, placebo-controlled trial of Gingko biloba in sexual dysfunction due to antidepressant drugs," Human Psychopharmacology, vol. 19, no. 8, pp. 545-548, 2004.

[79] R. Mazaro-Costa, M. L. Andersen, H. Hachul, and S. Tufik, "Medicinal plants as alternative treatments for female sexual dysfunction: utopian vision or possible treatment in climacteric women?" Journal of Sexual Medicine, vol. 7, no. 11, pp. 3695$3714,2010$.

[80] National Institutes of Health, "Ntp technical report on the toxicology and carcinogenesis studies of Ginkgo biloba extract 
(cas no. 90045-36-6)in $\mathrm{f} 344 / \mathrm{n}$ rats and b6c3f1/n mice(gavage studies)," 184 p. NIH Publication No. 13-5920, 2013.

[81] A. A. Hardigree and J. L. Epler, "Comparative mutagenesis of plant flavonoids in microbial systems," Mutation Research, vol. 58, no. 2-3, pp. 231-239, 1978.

[82] J. Birks, E. V. Grimley, and M. Van Dongen, “Ginkgo biloba for cognitive impairment and dementia," Cochrane Database of Systematic Reviews, no. 4, Article ID CD003120, 2002.

[83] A. Fugh-Berman, "Herb-drug interactions," The Lancet, vol. 355, no. 9198, pp. 134-138, 2000.

[84] S. Bent, H. Goldberg, A. Padula, and A. L. Avins, "Spontaneous bleeding associated with Ginkgo biloba: a case report and systematic review of the literature," Journal of General Internal Medicine, vol. 20, no. 7, pp. 657-661, 2005.

[85] E. Leistner and C. Drewke, "Ginkgo biloba and ginkgotoxin," Journal of Natural Products, vol. 73, no. 1, pp. 86-92, 2010.

[86] National Institutes of Health, "MedlinePlus Herbs and Supplements: Ginkgo (Ginkgo biloba L.) [Internet]," 2013, http:// www.nlm.nih.gov/medlineplus/druginfo/natural/333.html.

[87] B. E. Rollin, "An ethicist's commentary on animal welfare versus food safety in collecting antler velvet," Canadian Veterinary Journal, vol. 42, no. 5, pp. 330-331, 2001.

[88] E. S. Williams, "Chronic wasting disease," Veterinary Pathology, vol. 42, no. 5, pp. 530-549, 2005.

[89] R. C. Angers, T. S. Seward, D. Napier et al., "Chronic wasting disease prions in eik antler velvet," Emerging Infectious Diseases, vol. 15, no. 5, pp. 696-703, 2009.

[90] S. E. Saunders, S. L. Bartelt-Hunt, and J. C. Bartz, "Occurrence, transmission, and zoonotic potential of chronic wasting disease," Emerging Infectious Diseases, vol. 18, no. 3, pp. 369-376, 2012.

[91] S. Kumar, R. Madaan, and A. Sharma, "Pharmacological evaluation of bioactive principle of Turnera aphrodisiaca," Indian Journal of Pharmaceutical Sciences, vol. 70, no. 6, pp. 740-744, 2008.

[92] R. Arletti, A. Benelli, E. Cavazzuti, G. Scarpetta, and A. Bertolini, "Stimulating property of Turnera diffusa and Pfaffia paniculata extracts on the sexual behavior of male rats," Psychopharmacology, vol. 143, no. 1, pp. 15-19, 1999.

[93] GPHIN, Kazakhstan has forbidden import of smoking grassy mixes, communication posted on 2010/01/21 from Kazakhstan (in Russian), 2010.

[94] O. Corazza, S. Assi, P. Simonato et al., "Promoting innovation and excellence to face the rapid diffusion of novel Psychoactive substances in the EU: the outcomes of the reDNet project," Human Psychopharmacology, vol. 28, no. 4, pp. 317-323, 2013.

[95] F. Schifano, A. Ricciardi, O. Corazza et al., "New drugs and role of the web: psychonaut Web Mapping Project," Rivista di Psichiatria, vol. 45, no. 2, pp. 88-93, 2010.

[96] V. Auwärter, S. Dresen, W. Weinmann, M. Müller, M. Pütz, and N. Ferreirós, "“Spice” and other herbal blends: harmless incense or cannabinoid designer drugs?" Journal of Mass Spectrometry, vol. 44 , no. 5, pp. 832-837, 2009.

[97] C. R. Ossian, "The Most Beautiful of Flowers (review of Water Lilies and Lotuses in ancient Egypt)," KMT Magazine, vol. 1, pp. 48-59, 1999.

[98] W. A. Emboden, "Transcultural use of narcotic water lilies in ancient Egyptian and Maya drug ritual," Journal of Ethnopharmacology, vol. 3, no. 1, pp. 39-83, 1981.

[99] J. Waynberg, "Yohimbine vs. muira puama in the treatment of sexual dysfunction," The American Journal of Natural Medicine, vol. 1, pp. 8-9, 1994.
[100] J. Waynberg and S. Brewer, "Effects of Herbal vX on libido and sexual activity in premenopausal and postmenopausal women," Advances in Therapy, vol. 17, no. 5, pp. 255-262, 2000.

[101] C. M. Meston and J. R. Heiman, "Ephedrine-activated physiological sexual arousal in women," Archives of General Psychiatry, vol. 55, no. 7, pp. 652-656, 1998.

[102] M. Scibona, P. Meschini, S. Capparelli, C. Pecori, P. Rossi, and G. F. Menchini Fabris, "L-arginine and male infertility," Minerva Urologica e Nefrologica, vol. 46, no. 4, pp. 251-253, 1994.

[103] "European monitoring centre for drugs and drug addictions," Annual Report on the State of the Drugs Problem in Europe, Lisbon, Portugal, 2012.

[104] GPHIN, Health food is contained forbidding medicine changing a name sell again and again, communication posted on 2010/07/28 from Taiwan, 2010.

[105] GPHIN, Nationwide Track and Trace System Urgently Needed, communication posted on 2013/07/01 from United States, 2013.

[106] F. Schifano, P. Deluca, L. Agosti, G. Martinotti, J. M. Corkery, B. Alex et al., "Psychonaut 2002 Research Group. New trends in the cyber and street market of recreational drugs? The case of 2C-T-7 ("Blue Mystic")," Journal of Psychopharmacology, vol. 19, no. 6, pp. 675-679, 2005.

[107] I. Sáenz de Tejada, J. Angulo, S. Cellek et al., "Pathophysiology of erectile dysfunction," Journal of Sexual Medicine, vol. 2, no. 1, pp. 26-39, 2005. 

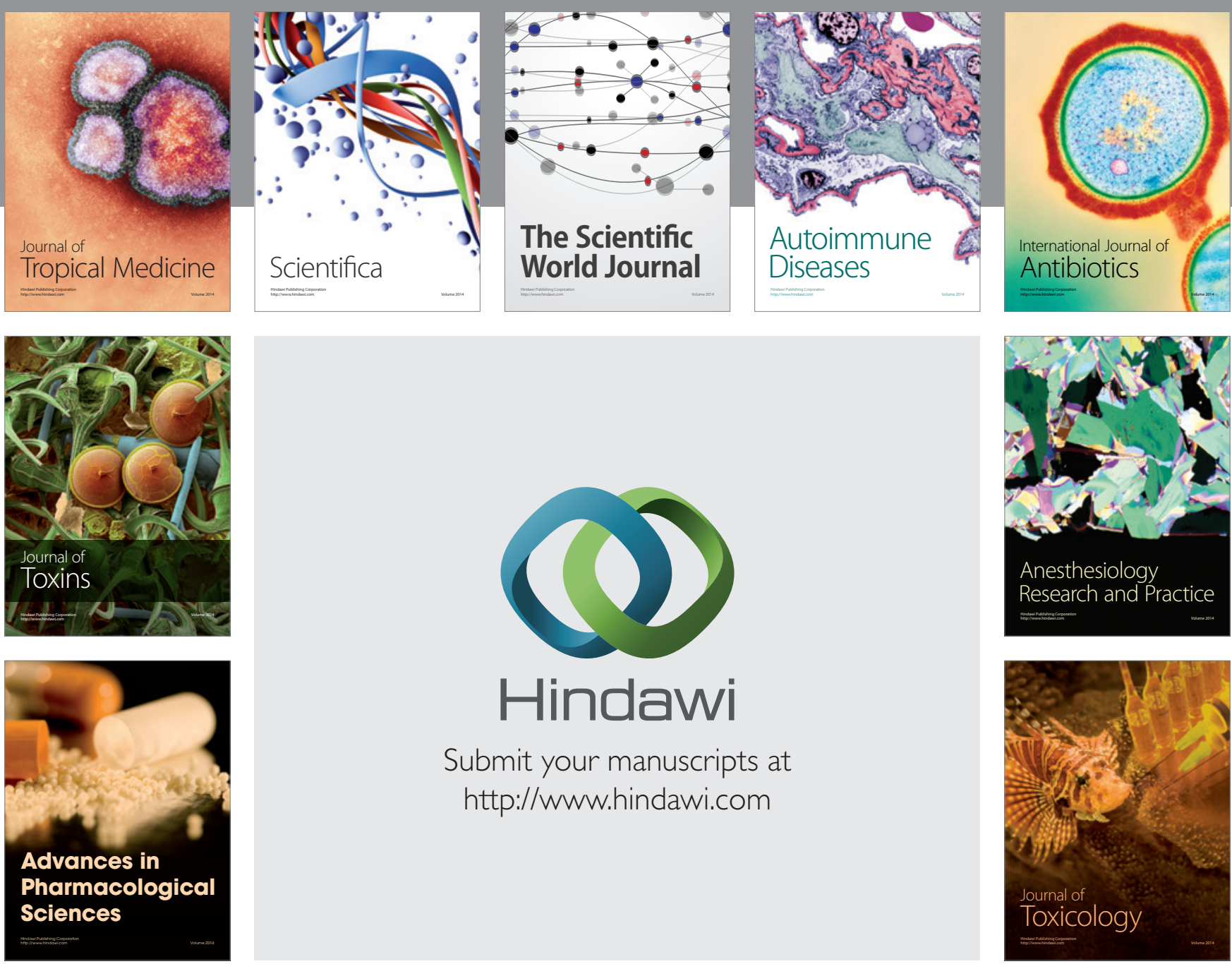

\section{Hindawi}

Submit your manuscripts at

http://www.hindawi.com
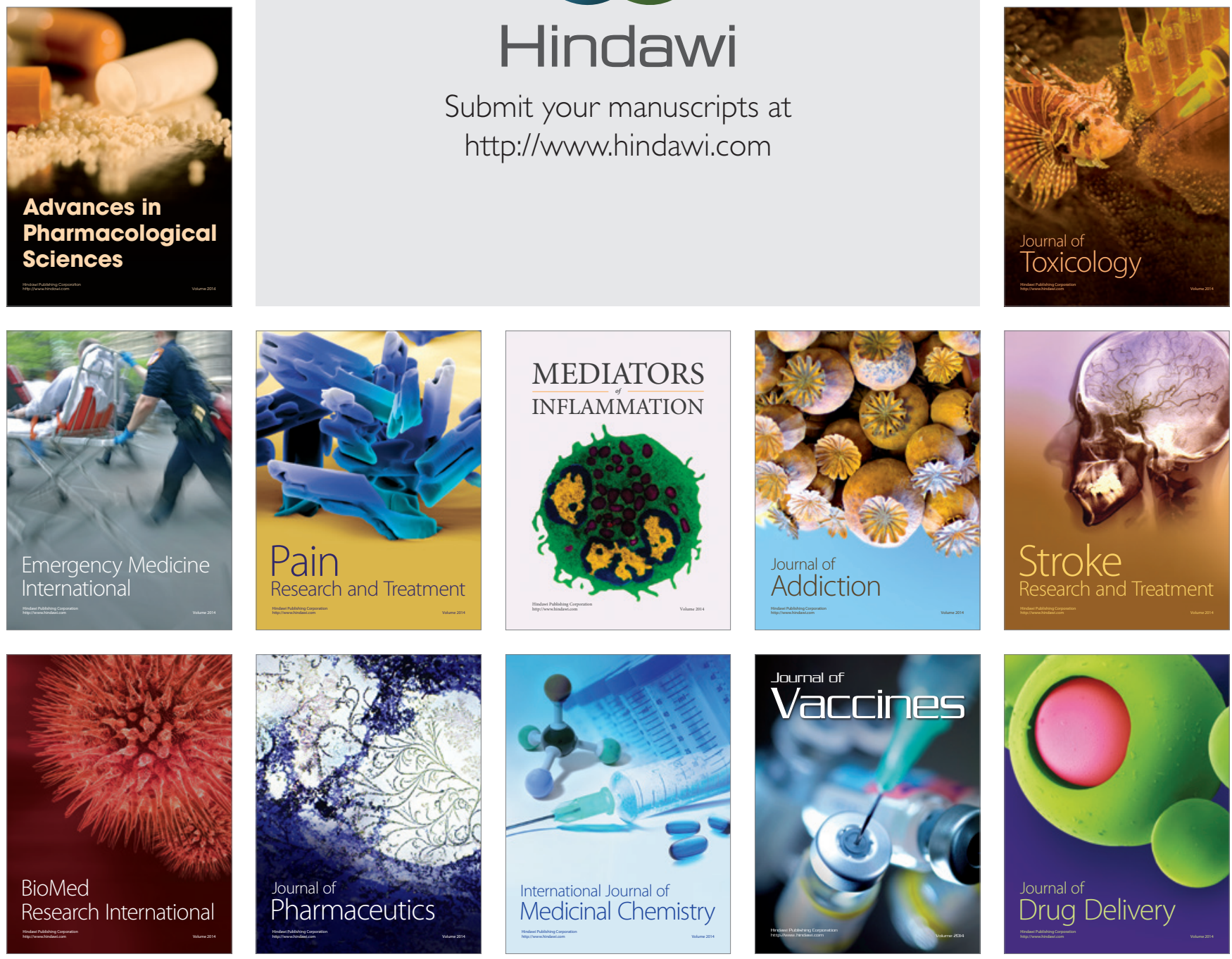